\title{
Biohydrogen Production from Pineapple Biomass Residue using Immobilized Co-culture of Clostridium sporogenes and Enterobacter aerogenes
}

\author{
Nur Kamilah Abd Jali1 ${ }^{1}$, Umi Aisah Asli*2,3, Haslenda Hashim ${ }^{1,4}$, Aishah Abd Jali1 ${ }^{1,2}$, Arshad Ahmad ${ }^{1,2}$, \\ Aidee Kamal Khamis ${ }^{3}$ \\ ${ }^{1}$ Faculty of Chemical and Energy Engineering, Universiti Teknologi Malaysia, 81310 Johor Bahru, Johor, \\ Malaysia \\ ${ }^{2}$ Centre of Hydrogen Energy, Institute of Future Energy, Universiti Teknologi Malaysia, 81310 Johor Bahru, \\ Johor, Malaysia \\ ${ }^{3}$ Innovation Centre in Agritechnology for Advanced Bioprocess (ICA), UTM Pagoh Research Center, 86400 \\ Pagoh, Malaysia \\ ${ }^{4}$ Process Systems Engineering Centre, Universiti Teknologi Malaysia, 81310 Johor Bahru, Johor, Malaysia \\ *Corresponding author: umiaisah@cheme.utm.my
}

\section{Article History}

Received: Jan 10, 2018

Received in revised form: July 04, 2018

Accepted: July 5, 2018

Published: July 30, 2018

\begin{abstract}
In this study, the co-culture bacteria of Clostridium sporogenes and Enterobacter aerogenes were immobilized onto two different support materials: loofah sponge and activated carbon (AC) sponge. Both immobilized co-cultures were used in the batch fermentation of pineapple residues for biohydrogen production. The performance of both immobilized loofah and $\mathrm{AC}$ sponge was compared with free cell (FC) co-culture in terms of biohydrogen cumulative production and production rate within $48 \mathrm{hr}$ fermentation time. It was found that the immobilized co-culture on AC sponge produced the highest rate of biohydrogen of $35.9 \mathrm{mmol} / \mathrm{hr} / \mathrm{L}_{\text {substrate }}$ compared to loofah and $\mathrm{FC}$ co-culture after $24 \mathrm{hr}$ fermentation. However, in terms of preservation of biohydrogen production rate, loofah as a support showed better consistency in terms of performance for $48 \mathrm{hr}$ fermentation time compared to AC. This study also showed that the $\mathrm{pH}$ of substrate has a relation to the optical density $\left(\mathrm{OD}_{600}\right)$ reduction of the bacteria, which could affect biohydrogen production rate.
\end{abstract}

Keywords: Batch fermentation, bacteria co-culture, immobilization, biohydrogen production.

\subsection{INTRODUCTION}

Biohydrogen is an alternative energy that can be produced by biological routes such as fermentation from renewable feedstock like agricultural waste, food waste, industrial waste, and municipal waste. Biological process might have a lower production rate than other processes but it is worthy as the operational cost is much lower with better environmental benefits. As fermentation process can be carried out at ambient pressure and temperature conditions, energy consumption is not intensive; hence, the process holds high potential to be commercialized in future energy production.

There are two main routes of fermentation: aerobic (presence of oxygen) and anaerobic (absence of oxygen). Compared to aerobic, anaerobic fermentation commonly has better performance of organic compound conversion to hydrogen with the utilization of bacteria through acidogenesis and acetogenesis processes. Anaerobic microorganisms such as anaerobic fermentative bacteria are commonly used in anaerobic fermentation because they are able to utilize carbon substrates to release hydrogen and also byproducts [1]. Hydrogen-producing bacteria such as Clostridium $s p$. is the most well-known bacteria that is suitable for higher biohydrogen production [2]. In order to maximize the production in short fermentation time, co-culture technique is the best option as it may improve culturing and cell behavior [3,4]. 
Co-culture bacteria can be used either in a free or an immobilized form on suitable support materials. Currently, immobilized cell has been widely used for hydrogen production either in laboratory or industrial scale as an alternative to enhance microorganisms' activity in a fermentation system [2-17]. The most applied method for immobilization is cell entrapment $[4-8,16,18,20-23]$, in which microorganisms are enclosed in a porous matrix to allow cell-substrate diffusion and cells-products away from the material utilized. The advantages of immobilized cultures include reducing risk of contamination [21], higher metabolic activity [4], reusable [4, 5], and easier separation of solids and liquids [22].

In this study of the production of biohydrogen, immobilized method was applied to sustain the bacteria for the maximum utilization of pineapple substrate. Two types of support materials, loofah sponge and activated carbon (AC) sponge, were used for the new combination co-culture of Enterobacter aerogenes (E. aerogenes) and Clostridium sporogenes ( $C$. sporogenes). E. aerogenes was selected because it is a facultative anaerobe that can survive if oxygen is present. $E$. aerogenes commonly utilizes oxygen and simultaneously provides anaerobic condition to a strict anaerobe, $C$. sporogenes. The main objective of this work is to compare biohydrogen production of the immobilized co-culture on both support materials with free co-culture. The optical density of bacteria and $\mathrm{pH}$ condition of substrate were monitored to relate both factors to biohydrogen performance.

\subsection{METHODOLOGY}

\subsection{Pineapple Substrate Preparation}

Fresh pineapple waste was obtained from fruit stalls at a local market. In this experiment, only pineapple peels were used and subjected to steam heat pretreatment (autoclaved). The pineapple peels were chopped into small pieces. Afterwards, the chopped pineapple waste was crushed using a steel blender (Waring Commercial Blender) with distilled water in the ratio of 1:2. Next, the mixture was filtrated to obtain the hydrolysate or extract for characterization analysis. After characterization, the hydrolysate was stored in a refrigerator at $4{ }^{\circ} \mathrm{C}$ and restored to ambient temperature $\left(25^{\circ} \mathrm{C}\right)$ prior to use. The substrate was neutralized to $\mathrm{pH} 7$ every time before it was mixed with inoculum for fermentation.

\subsection{Co-culture and Immobilization Preparation}

Facultative anaerobe (E. aerogenes-ATCC 13048) and a strict anaerobe (C. sporogenes - ATCC 19404) purchased from Microbiologics (Saint Cloud, USA) were utilized as the co-culture to perform fermentation process. Commercial loofah sponge and $\mathrm{AC}$ sponge were used as the support materials to retain the co-culture bacteria. For inoculum (co-culture) preparation, both bacteria were activated onto the agar before cultivated into nutrient broth. Next, approximately $0.2 \pm$ $0.1\left(\mathrm{OD}_{600}\right)$ of E. aerogenes and $C$. sporogenes were mixed carefully and aseptically, and then incubated for $24 \mathrm{hr}$ (overnight) before immersion of the support materials. Meanwhile, loofah and activated carbon (AC) sponges were cut into pieces $(1 \pm 0.2 \mathrm{~cm} \times 1 \pm 0.2 \mathrm{~cm})$ and soaked in boiling water for $30 \mathrm{~min}$. After that, the sponges were washed under tap water before left in distilled water for $24 \mathrm{hr}$ (changed 3 to 4 times). This is essential to remove all fine suspended particles [8]. Next, the sponges were dried in an oven at $70{ }^{\circ} \mathrm{C}$ overnight before dried uniformly in a desiccator. The sponges were then soaked inside $90 \mathrm{ml}$ of nutrient broth (30\% of working volume) and incubated for another $24 \mathrm{hr}$ at 130 $\mathrm{rpm}$ and $37{ }^{\circ} \mathrm{C}$ prior to use. The sponges were mixed with the substrate for further fermentation. The inoculum was directly used or mixed with pineapple substrate for mobilize co-culture set-up without soaking any sponge for immobilization.

\subsection{Experimental Condition (Batch Set-Up)}

The schematic diagram of experimental setup is shown in Figure 1. The fermentation of collected pineapple waste was carried out in a $500 \mathrm{ml}$ Dreschel bottle with the working volume of $300 \mathrm{ml} .210 \mathrm{ml}$ of pineapple waste was first added to a $500 \mathrm{ml}$ Dreschel bottle and the inoculum or/and immobilized sponges were then added to the substrate. The initial $\mathrm{pH}$ of the substrate was adjusted using $0.5 \mathrm{M}$ sodium hydroxide $(\mathrm{NaOH})$ to achieve the initial $\mathrm{pH}$ of 7 . Nitrogen sparging was applied to provide anaerobic condition for the fermentation process and the bottles were sealed and placed in a water bath to maintain the culture medium at $33 \pm 1{ }^{\circ} \mathrm{C}$. Mixing was provided by a stirring magnetic bar in the bottle. In this experiment, gas purging was only applied at the early stage of the set-up and manual mixing was applied at every $12 \mathrm{hr}$ interval. The volume of biogas collected was read from the scales on the gas collection measuring cylinder through water displacement method at $12 \mathrm{hr}$ interval. The volume of water displaced in the measuring cylinder was determined as the volume of biohydrogen produced whereas the gas captured in polyvinylidene fluoride (PVDF) gas bag was analyzed using gas chromatography (Agilent Technologies, 6890N, Network GC System) equipped with a thermal conductivity detector (TCD) to obtain the composition and amount of biohydrogen produced. 


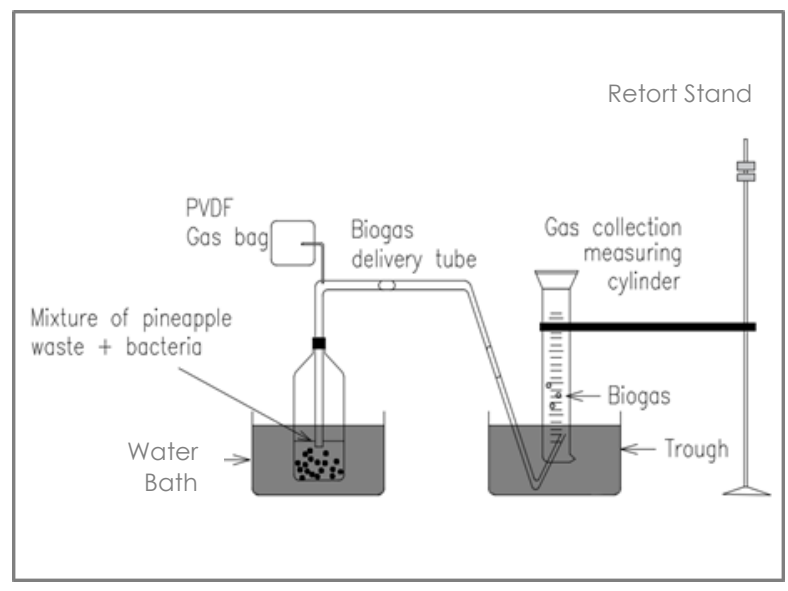

Figure 1. Schematic diagram of the experimental set up

\subsection{RESULTS AND DISCUSSION}

Figure 2 presents cumulative biohydrogen production of immobilized activated carbon (AC), loofah sponge (LS), and free cell (FC) throughout the experiment. AC and LS reached the maximum production during $48 \mathrm{hr}$ fermentation time while $\mathrm{FC}$ reached the maximum cumulative biohydrogen at $36 \mathrm{hr}$ and decreased slightly at $48 \mathrm{hr}$ fermentation time. For FC, during $48 \mathrm{hr}$ fermentation time, the volume of biogas captured increased but the biohydrogen percentage was low due to high content of carbon dioxide $\left(\mathrm{CO}_{2}\right)$. The decrement of biohydrogen production might be due to exhausted nutrient that potentially occurred after a certain extended period. In this stage, a metabolic shift of biohydrogen-producing pathways to biohydrogen-inhibiting biochemical reaction occurred [24]. Biohydrogen formation could be reduced by the formation of fatty acid with high $\mathrm{CO}_{2}$ content in biogas composition.

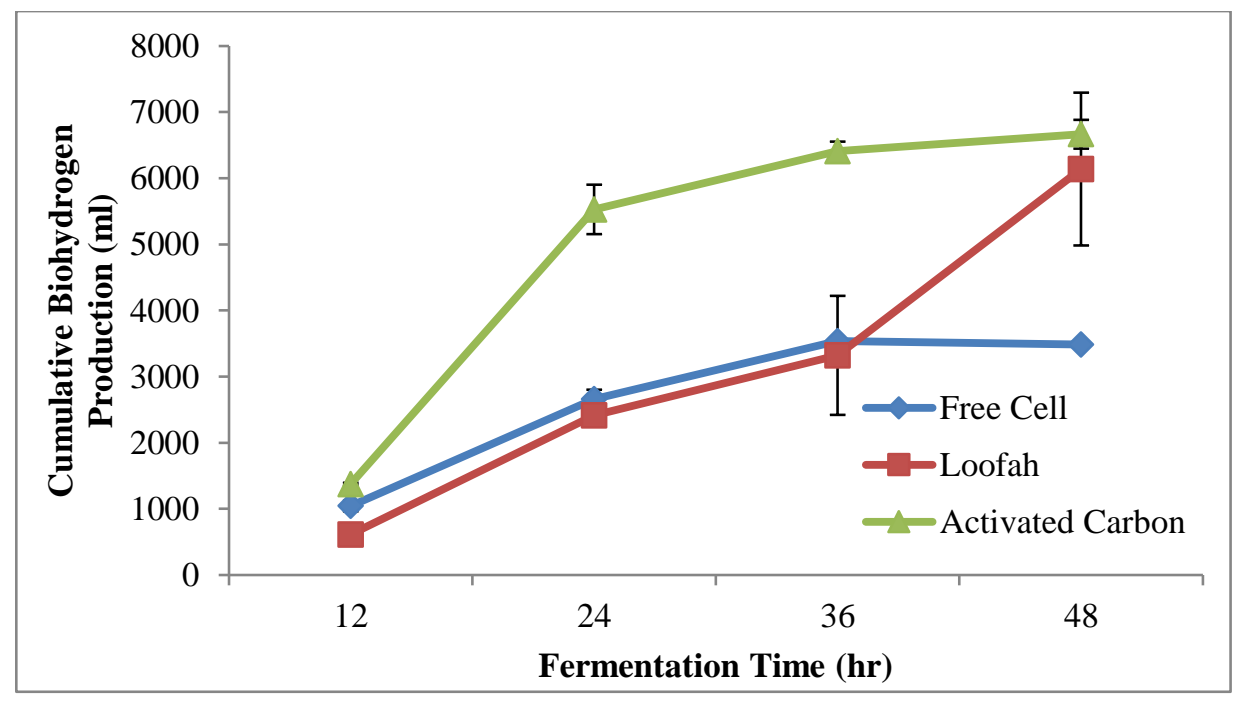

Figure 2. Cumulative biohydrogen production for different immobilized support materials

Figure 3 shows the biohydrogen production rate obtained for FC co-culture, as well as immobilized co-culture onto LS and $\mathrm{AC}$ sponge. As can be seen in Fig. 3, the highest rate obtained using immobilized AC sponge was obtained at 35 $\mathrm{mmol} / \mathrm{hr} / \mathrm{L}_{\text {substrate }}$ after $24 \mathrm{hr}$ fermentation time. However, the production rate dropped approximately $22 \%$ after $36 \mathrm{hr}$ and further decreased by approximately $16 \%$ towards the end of fermentation. Meanwhile, immobilized LS facilitated a consistent increase of biohydrogen production rate from only $7.86 \mathrm{mmol} / \mathrm{hr} / \mathrm{L}_{\text {substrate }}$ at the early stage and reached 21.54 $\mathrm{mmol} / \mathrm{hr} / \mathrm{L}_{\text {substrate }}$ after $48 \mathrm{hr}$ fermentation time, which is up to $60 \%$ increment. For FC co-culture, the highest rate was achieved at $12 \mathrm{hr}$ fermentation time and dropped at every interval until the end of observation. The different production 
trends by immobilized co-culture on the support materials of AC and LS might be due to the retention on the sponge [8]. It could also be due to imperfect immobilized cell loading amount that resulted in poor mass transfer and led to poor biohydrogen production [25].

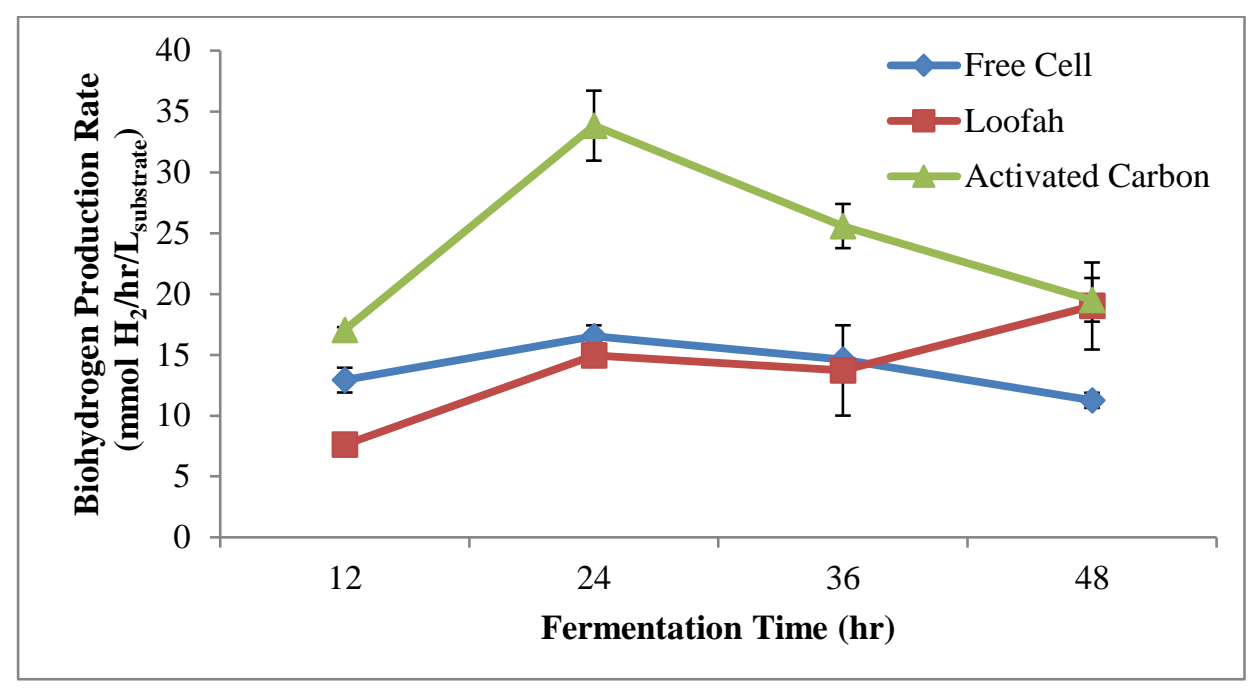

Figure 3. Biohydrogen production rate for different immobilized support materials

The relation of biohydrogen production rate with optical density $\left(\mathrm{OD}_{600}\right)$ of bacteria and $\mathrm{pH}$ changes of the substrate was studied, and this is shown in Figure 4. The graphs showed that the highest OD concentration of the co-culture was mostly achieved after $24 \mathrm{hr}$ fermentation time and afterwards they started to reach the stationary phase. This indicated the growth of the bacteria during the middle of exponential stage and started to utilize the pineapple substrate, which produced high amount of biohydrogen. Slightly lower biohydrogen started to be produced as the inoculum grew slightly before reaching the stationary phase.

In addition, the production also remained high during the acidogenesis stage for all conditions based on the reduction of $\mathrm{pH}$ from the initial $\mathrm{pH}$ value. The reduction of $\mathrm{pH}$ occurred due to the production of organic acid as the byproduct instead of biohydrogen. Clearly, methanogenic hydrogen consumers are absent in this fermentation system because no methane was detected in this study and biohydrogen reached the maximum production at a certain interval.

The $\mathrm{pH}$ reduction started when the inoculum was mixed with the substrate and it is in contrast with the OD 600 of the bacteria, which increased gradually until $36 \mathrm{hr}$ fermentation time. Initial $\mathrm{pH}$ is a very important parameter as it will determine the survival of the inoculum introduced. As it is introduced at right or suitable $\mathrm{pH}$, it will grow and acidogenesis will start. All samples showed that the $\mathrm{pH}$ dropped at only moderately acidic $\mathrm{pH}$ around 5.8 to 6 and the cumulative biohydrogen produced was higher, which is similar to a previous discussion that moderately acidic $\mathrm{pH}$ is good for inhabiting methanogenic activity and enhancing hydrogen-producing bacteria to produce biohydrogen [20, 25]. In this study, the $\mathrm{pH}$ dropped during $12 \mathrm{hr}$ and $24 \mathrm{hr}$ fermentation time, in which the production of $\mathrm{CO}_{2}$ is high or maximum. It suggests that the reduction of $\mathrm{pH}$ happened due to the production of soluble metabolites [16] and also due to the increase of $\mathrm{CO}_{2}$ content in biogas.

Overall, it could be emphasized that in this experiment, the co-culture inoculum seems to have taken a short period of time (within $24 \mathrm{hr}$ ) to survive in the substrates, despite that inoculum usually takes some time to adapt to the environment before starting to produce biohydrogen $[20,26,27]$. The initial $\mathrm{OD}_{600}$ of every co-culture used was in the range of $0.2-$ 0.3 . After $12 \mathrm{hr}$, the $\mathrm{OD}_{600}$ increased and doubled at $24 \mathrm{hr}$ and started to decrease after $36 \mathrm{hr}$. 


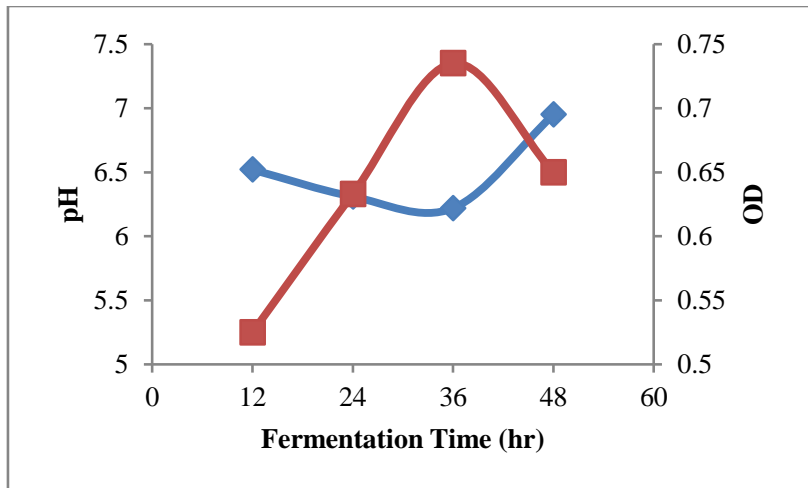

(a)

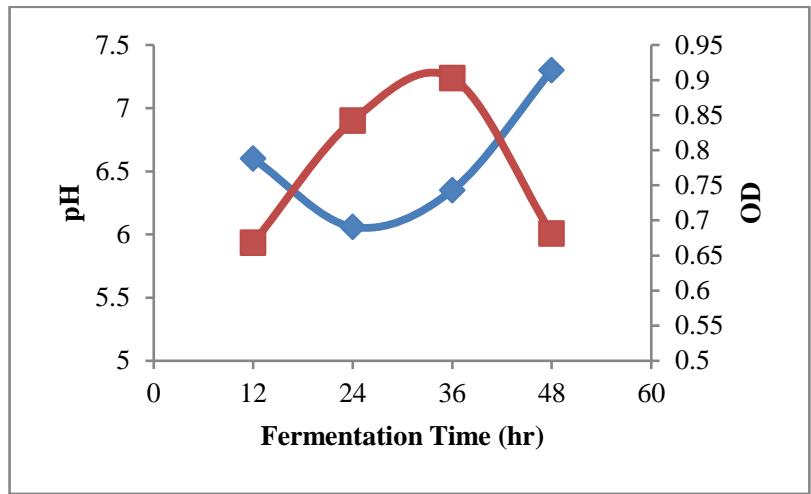

(b)

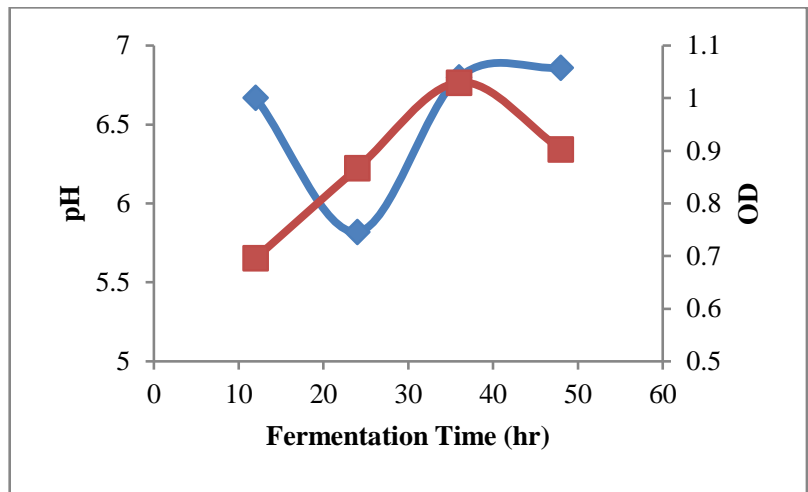

(c)

Figure 4. Relationship of biohydrogen production rate with optical density and pH changes for (a) free cell, (b) immobilized loofah sponge, and (c) activated carbon sponge

\subsection{CONCLUSION}

The biohydrogen production rate using co-culture by immobilization reached up to $39 \mathrm{mmol} / \mathrm{hr} / \mathrm{L}_{\text {substrate }}$. The combination of co-culture $E$. aerogenes and $C$. sporogenes worked well with the utilization pineapple substrate. Immobilization using AC sponge was determined as a better support material compared to LS, which could enhance approximately $67 \%$ of the production rate compared to FC co-culture.

\section{Acknowledgements}

The authors acknowledge the support by the Malaysian Ministry of Higher Education (MOHE) and GUP UTM research grant (Q.J10030000.2644.06J00, Q.J10030000.2644.09J17, and Q.J130000.2544.09H24) for funding the research. 


\section{References}

[1] P. Sivagurunathan, P. Anburajan, J. H. Park, G. Kumar, H. D. Park, and S. H. Kim (2017). Mesophilic biogenic H2 production using galactose in a fixed bed reactor. Int. J. Hydrogen Energy, vol. 42, no. 6, pp. 3658-3666.

[2] K. Bru et al. (2012). "nnovative $\mathrm{CO} 2$ pretreatment for enhancing biohydrogen production from the organic fraction of municipal solid waste (OFMSW). Int. J. Hydrogen Energy, vol. 37, no. 19, pp. 14062-14071.

[3] L. Goers, P. Freemont, and K. M. Polizzi. (2014). Co-culture systems and technologies: taking synthetic biology to the next level. J. R. Soc. Interface, vol. 11, no. 96.

[4] P.M. Kao, B.-M. Hsu, K.-H. Huang, C.-W. Tao, C.-M. Chang, and W.-T. Ji. (2014). Biohydrogen Production by Immobilized Co-culture of Clostridium Butyricum and Rhodopseudomonas Palustris. Energy Procedia, vol. 61, pp. 834-837.

[5] G. Balachandar, N. Khanna, and D. Das. (2013). Chapter 6 - Biohydrogen Production from Organic Wastes by Dark Fermentation, 1st ed., Elsevier B.V.

[6] T. Keskin, E. Aksöyek, and N. Azbar. (2011). Comparative analysis of thermophilic immobilized biohydrogen production using packed materials of ceramic ring and pumice stone. Int. J. Hydrogen Energy, vol. 36, no. 23, pp. 15160-15167.

[7] T. Keskin, L. Giusti, and N. Azbar, “Continuous biohydrogen production in immobilized biofilm system versus suspended cell culture,” Int. J. Hydrogen Energy, vol. 37, no. 2, pp. 1418-1424, 2012.

[8] A. A. Rahma,. (2013). Biohydrogen Production by Modified Anaerobic Fluidized Bed Reactor ( AFBR ) Using Mixed Bacterial Cultures in Thermophilic Condition . Master Thesis. Retrieved from http://library.iugaza.edu.ps/thesis/111749.pdf.

[9] L. Singh, M. F. Siddiqui, A. Ahmad, M. H. A. Rahim, M. Sakinah, and Z. A. Wahid. (2013). Biohydrogen production from palm oil mill effluent using immobilized mixed culture, J. Ind. Eng. Chem., vol. 19, no. 2, pp. 659-664.

[10] L. Singh, Z. A. Wahid, M. F. Siddiqui, A. Ahmad, M. H. A. Rahim, and M. Sakinah. (2013). Biohydrogen production from palm oil mill effluent using immobilized Clostridium butyricum EB6 in polyethylene glycol, Process Biochem., vol. 48, no. 2, pp. 294-298.

[11] B. Hu. (2013). Biological Hydrogen Production via Self Immobilized Bacteria, J. Chem. Inf. Model., vol. 53, no. 9, pp. $1689-1699$.

[12] a. Tenca, a. Schievano, F. Perazzolo, F. Adani, and R. Oberti. (2011). Biohydrogen from thermophilic co-fermentation of swine manure with fruit and vegetable waste: Maximizing stable production without pH control, Bioresour. Technol., vol. 102, no. 18, pp. 8582-8588.

[13] N. Basak, A. K. Jana, D. Das, and D. Saikia. (2014). Photofermentative molecular biohydrogen production by purple-non-sulfur (PNS) bacteria in various modes: The present progress and future perspective, Int. J. Hydrogen Energy, vol. 39, no. 13, pp. 6853-6871.

[14] P. Koskinen. (2008). The Development and Microbiology of Bioprocesses for the Production of Hydrogen and Ethanol by Dark Fermentation.

[15] H. Argun and F. Kargi. (2011). Bio-hydrogen production by different operational modes of dark and photo-fermentation : An overview,” Int. J. Hydrogen Energy, vol. 36, no. 13, pp. 7443-7459.

[16] P. T. Sekoai and E. B. Gueguim Kana. (2013). A two-stage modelling and optimization of biohydrogen production from a mixture of agromunicipal waste, Int. J. Hydrogen Energy, vol. 38, no. 21, pp. 8657-8663.

[17] L. Xiao, Z. Deng, K. Y. Fung, and K. M. Ng. (2013). Biohydrogen generation from anaerobic digestion of food waste," Int. J. Hydrogen Energy, vol. 38, no. 32, pp. 13907-13913.

[18] W. Han, Z. Wang, H. Chen, X. Yao, and Y. Li. (2011). Simultaneous Biohydrogen and Bioethanol Production from Anaerobic Fermentation with Immobilized Sludge, vol. 2011, pp. 1-6.

[19] L. Zhao et al. (2011). Enhanced bio-hydrogen production by immobilized Clostridium sp. T2 on a new biological carrier, Int. J. Hydrogen Energy, vol. 37, no. 1, pp. 162-166.

[20] M. S. de Graaff, H. Temmink, G. Zeeman, and C. J. N. Buisman. (2010). Anaerobic Treatment of Concentrated Black Water in a UASB Reactor at a Short HRT, Water, vol. 2, pp. 101-119.

[21] E. Topics. (2007). Immobilisation of yeasts for continuous fermentation,” pp. 418-425.

[22] L. Singh, Z. A. Wahid, M. F. Siddiqui, A. Ahmad, M. H. A. Rahim, and M. Sakinah.(2013). Application of immobilized upflow anaerobic sludge blanket reactor using Clostridium LS2 for enhanced biohydrogen production and treatment efficiency of palm oil mill effluent, Int. J. Hydrogen Energy, vol. 38, no. 5, pp. 2221-2229.

[23] P. Sekoai, K. Yoro, and M. Daramola. (2016). Batch Fermentative Biohydrogen Production Process Using Immobilized Anaerobic Sludge from Organic Solid Waste, Environments, vol. 3, no. 4, p. 38. 
[24] “Immobilization Studies Using Nanomagnetite to Enhance Biohydrogen Production Trevor Seelert Department of Chemical Engineering McGill University , Montreal,” no. September, 2013.

[25] C. Mao, Y. Feng, X. Wang, and G. Ren. (2015). Review on research achievements of biogas from anaerobic digestion, Renew. Sustain. Energy Rev., vol. 45, pp. 540-555.

[26] A. Babaee and J. Shayegan. (2011). Effect of Organic Loading Rates (OLR) on Production of Methane from Anaerobic Digestion of Vegetables Waste, World Renew. energy Congr., no. November, pp. 411-417.

[27] N. H. M. Yasin, T. Mumtaz, M. A. Hassan, and N. Abd Rahman (2013). Food waste and food processing waste for biohydrogen production: A review, J. Environ. Manage., vol. 130, no. June 2011, pp. 375-385. 